\title{
Single session conditioning of the nictitating membrane in the rabbit: Effect of intertrial interval
}

\author{
John Brelsford, Jr. and John Theios \\ UNIVERSITY OF TEXAS
}

\begin{abstract}
102 Ss were assigned to 3 groups and classically conditioned with a 45 sec., a 111 sec., or a 5 min. ITI. The CS was an $88 \mathrm{db}$ buzzer, and the US was shock. For any given subject all conditioning trials took place within a single session. It was found that a U-shaped function described the relationship between trials to an acquisition criterion and ITI, with the 111 sec.group performing better than either of the other groups.

\section{Problem}

Several recent studies (Gormezano et al., 1962; Papsdorf et al., 1964; Schneiderman \& Gormezano, 1964) have shown that the nictitating membrane of the rabbit can be reliably classicially conditioned. These studies have usually been conducted with a delayed procedure employing a tone for the CS and an air puff as the US. Typically, performance curves have reached 70\%-100\% after 6-8 daily sessions of 70-80 trials per day. One notable factor in all of these studies is that the acquisition of the membrane response takes place relatively slowly. Even after 300-400 trials, Ss may perform below the $100 \%$ level. One possible reason for this slowness of acquisition may be the fact that Ss are run in multiple sessions rather than allowing all acquisition to take

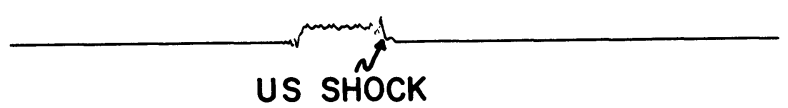

\section{$I_{(1 \mathrm{CM} .)} 05 \mathrm{VOLT}$}
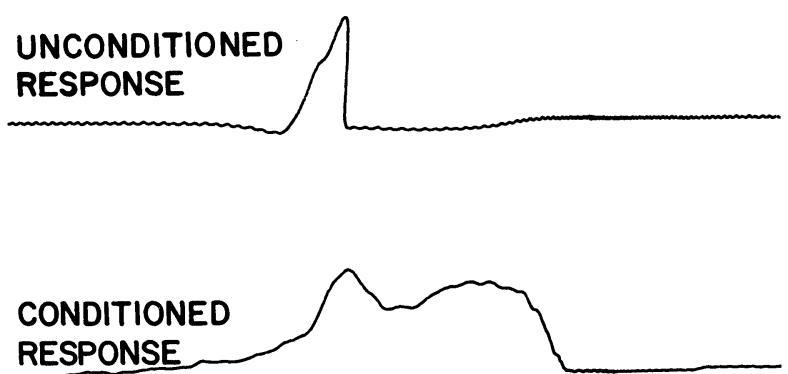

CS BUZZER 340 MSEC.

Fig. 1. Typical record of a $\mathrm{CR}$ and an error. place within the confines of a single conditioning session. In certain instances, where it seems desirable to obtain measures of acquisition unmarred by the effects of intersession forgetting and stimulus changes, single session conditioning might be in order. In the present study it was desired to use single session conditioning while investigating the effect of intertrial interval (ITI) on the acquisition of the rabbit's membrane response. As yet, the effect of ITI on the acquisition of this response has not been reported. All of the above studies used variable ITI values with means ranging from $20 \mathrm{sec}$. (Gormezano et al., 1962). to $1 \mathrm{~min}$. (Papsdorf et al., 1964). In order to obtain conditioning in a single session in the present study, two steps were taken to increase the rate of acquisition of the conditioned response. First, a constant ITI value was used rather than a variable one. Second, on a suggestion from Gormezano, electric shock was used as the US rather than the more common air puff. It was felt that, with these changes in ITI and US, the learning rate would be increased to the extent that a high level of conditioning could be obtained in a single session.

\section{Method}

Gormezano (1964) has described in detail the apparatus used in conditioning the nictitating membrane of the rabbit. Briefly, Ss were placed in a Plexiglas restraining device, with their heads inserted through an adjustable opening in the front and the pinnae of both ears clamped to the top of the device. This prevented gross head and body movements from taking place. Two shock electrodes, made of 1-in safety pins, were fastened about $1 / 2$ in from S's right eye, superiorly and inferiorly. A muzzle-like device holding a miniature, precision, rotary potentiometer was mounted on the S's head. The shaft of the potentiometer was mechanically attached to a nylon loop sutured in the right nictitating membrane. Thus, when the membrane moved, the potentiometer induced a voltage change which was amplified and recorded by an Offner 542 Dynograph with a paper speed of $250 \mathrm{~cm}$ per sec.

The Ss were 102 male and female New Zealand rabbits, either albino, red or of mixed pigmentation. Ss ranged in weight from 3-5 lb and were run singly or in pairs in a sound-attenuated, chamber 28 by 21 by 21 in. Ss were divided into three groups with one group having a 45 sec. ITI $(\mathrm{N}=16)$, one group having a $111 \mathrm{sec}$. ITI $(\mathrm{N}=70)$, and one group having a $5 \mathrm{~min}$. ITI $(\mathrm{N}=16)$. The US was a single spike electric shock of $1 \mathrm{msec}$. duration with a peak open circuit voltage of 150. The US was generated by a Bird Electronic Inductorium (No. 70925). The CS was an $88 \mathrm{db}$ buzzer with a duration of $340 \mathrm{msec}$. The CS-US interval was $250 \mathrm{msec}$.

Prior to conditioning Ss were pretested with several unpaired CS and US trials. No S blinked to CS or failed to blink to US on these trials. After the pretest, the single conditioning session began. Conditioning was continued until Ss had reached a criterion of at least 10 consecutive conditioned responses (CRs). A CR was defined as a pen deflection of at least $1 \mathrm{~mm}$ from the baseline in the interval from 25 msec. after CS onset to $10 \mathrm{msec}$. after the US onset. Typical samples of a CR and an error are given in Fig. 1. 


\section{Results}

Figure 2 presents the relationship between ITI and several measures of acquisition. It can be seen that there is a U-shaped function describing the relationship between level of performance and ITI value, with an ITI of $111 \mathrm{sec}$. resulting in better conditioning than either $45 \mathrm{sec}$. or $5 \mathrm{~min}$. An analysis of variance performed on the total number of errors before criterion yielded a significant $F$ ratio for ITI ( F, 4.92; df, 2/99; $<<.01)$, indicating that the differences in performance at the three levels of ITI are reliable ones. Analyses are not reported for the other three measures of acquisition depicted in Fig. 2 since they correlate highly with total errors. The differences among the groups can be seen in Fig. 3 which presents the mean learning curves.

\section{Diseussion}

It should be noted that, in this study, the ITI was highly correlated with the duration of the conditioning sessions. For the $45 \mathrm{sec}$. ITI group the conditioning session lasted a mean of $11 / 4 \mathrm{hr}$. For the $111 \mathrm{sec}$. group the sessions lasted a mean of about $2 \mathrm{hr}$. For the 5 min. group the conditioning sessions lasted a mean of about $7 \mathrm{hr}$. It might be speculated that, rather than performance being a direct function of ITI, the time spent in the conditioning session and ITI interact to produce the obtained U-shaped function. If performance increased monotonically with increases in ITI, and fatigue, or sleep, or some such detrimental variable increased monotonically with session length, then the resultant function could be U-shaped. The present study does not enable one to determine the unconfounded effects of ITI and session length on performance.

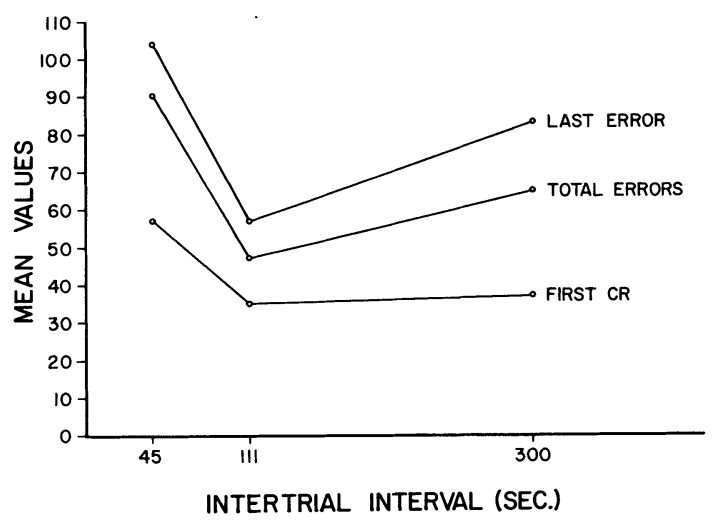

Fig. 2. Mean trial of first CR, mean total number of errors, and mean trial number of last error before criterion run as a function of intertrial interval.

In comparing the data collected in the present study with that from the studies mentioned earlier it can be seen that the acquisition rate is much faster with the

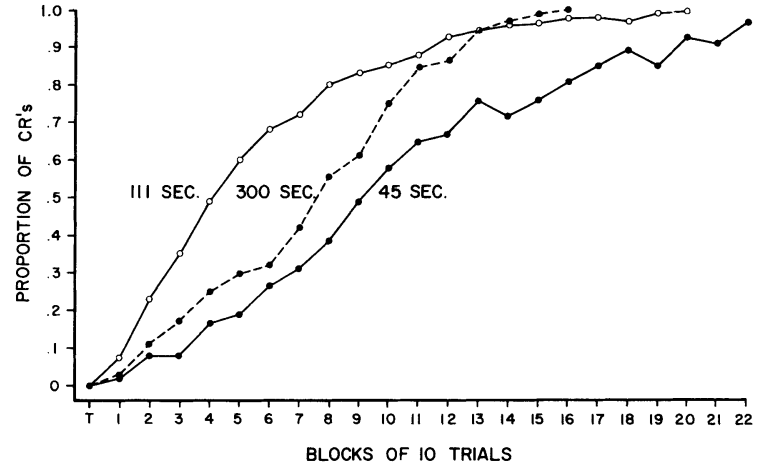

Fig. 3. Mean learning curves for the three groups.

present procedure than with previously used procedures. Under the best set of conditions in the present study, i. e., an ITI of $111 \mathrm{sec}$. and an $\mathrm{N}$ of 70, the mean number of trials to a criterion of 10 consecutive CRs was 66.74. Though there is no directly comparable analysis of the data in any of the earlier cited studies it seems safe to conclude that in none of the studies did the Ss reach a criterion of 10 consecutive CRs in nearly as few trials as in the present study. By employing shock for the US, holding the ITI constant, by using single session conditioning, and by using a short CS-US interval, the present experimenters were able to condition the nictitating membrane of the rabbit in many fewer trials than has been previously reported. Due to the absence of intersession decrements which tend to confound the course of acquisition, the present methodology would seem to be especially useful in studies involving mathematical analyses of the structure of acquisition data. At present the authors are using this methodology in investigating the trial by trial contingencies of the conditioning process in rabbits.

Referenees

GORMEZANO, I. Classical conditioning. In J. B. Sidowski (Ed), Experimental methods and instrumentation in psychology. New York: McGraw-Hill, 1964, in press.

GORMEZANO, I., SCHNEIDERMAN, N., DEAUX, E., \& FUENTES, I. Nictitating membrane: Classical conditioning and extinction in the albino rabbit. Science, 1962, 138, 33-34.

PAPSDORF, J., FISHBEIN, H., \& GORMEZANO, I. A comparison of an intermittent versus continuous $\mathrm{CS}$ in classical conditioning of the nictitating membrane response of the rabbit. Psychon. Sci., 1964, 1, 305-306.

SCHNEIDERMAN, N., \& GORMEZANO, I. Conditioning of the nictitating membrane of the rabbit as a function of CS-US interval. J, comp. physiol. Psychol., 1964, 57, 188-195.

Notes

1. Full credit for the development of the conditioning technique is due I. Gormezano. We gratefully acknowledge his technical assistance and instruction in the conditioning technique.

2. This investigation was supported by PHS Research Grant HD 00950 from the National Institute of Child Health and Human Development, Public Health Service. 